\title{
Implementing cardiovascular disease prevention guidelines to translate evidence-based medicine and shared decision making into general practice: theory-based intervention development, qualitative piloting and quantitative feasibility
}

Carissa Bonner $^{1 *}$, Michael Anthony Fajardo ${ }^{1}$, Jenny Doust ${ }^{2}$, Kirsten McCaffery ${ }^{1}$ and Lyndal Trevena ${ }^{1}$

\begin{abstract}
Background: The use of cardiovascular disease (CVD) prevention guidelines based on absolute risk assessment is poor around the world, including Australia. Behavioural barriers amongst GPs and patients include capability (e.g. difficulty communicating/understanding risk) and motivation (e.g. attitudes towards guidelines/medication). This paper outlines the theory-based development of a website for GP guidelines, and piloting of a new risk calculator/ decision aid.

Methods: Stage 1 involved identifying evidence-based solutions using the Behaviour Change Wheel (BCW) framework, informed by previous research involving $400 \mathrm{GPs}$ and 600 patients/consumers. Stage 2 co-developed website content with GPs. Stage 3 piloted a prototype website at a national GP conference. Stage 4 iteratively improved the website based on "think aloud" interviews with GPs and patients. Stage 5 was a feasibility study to evaluate potential efficacy (guidelines-based recommendations for each risk category), acceptability (intended use) and demand (actual use over 1 month) amongst GPs $(n=98)$.

(Continued on next page)
\end{abstract}

\footnotetext{
* Correspondence: carissa.bonner@sydney.edu.au

${ }^{1}$ The University of Sydney, Sydney School of Public Health, ASK-GP Centre of

Research Excellence, Rm 128 Edward Ford Building (A27), Sydney, NSW,

Australia

Full list of author information is available at the end of the article
}

(c) The Author(s). 2019 Open Access This article is distributed under the terms of the Creative Commons Attribution 4.0 International License (http://creativecommons.org/licenses/by/4.0/), which permits unrestricted use, distribution, and reproduction in any medium, provided you give appropriate credit to the original author(s) and the source, provide a link to the Creative Commons license, and indicate if changes were made. The Creative Commons Public Domain Dedication waiver (http://creativecommons.org/publicdomain/zero/1.0/) applies to the data made available in this article, unless otherwise stated. 


\begin{abstract}
(Continued from previous page)
Results: Stage 1 identified GPs as the target for behaviour change; the need for a new risk calculator/decision aid linked to existing audit and feedback training; and online guidelines as a delivery format. Stage 2-4 iteratively improved content and format based on qualitative feedback from GP and patient user testing over three rounds of website development. Stage 5 suggested potential efficacy with improved identification of hypothetical high risk patients (from 26 to 76\%) and recommended medication (from 57 to 86\%) after viewing the website ( $n=42$ ), but prescribing to low risk patients remained similar (from 19 to $22 \% ; n=37$ ). Most GPs (89\%) indicated they would use the website in the next month, and $72 \%$ reported using it again after one month $(n=98)$. Open feedback identified implementation barriers including a need for integration with medical software, low health literacy resources and pre-consultation assessment.

Conclusions: Following a theory-based development process and user co-design, the resulting intervention was acceptable to GPs with high intentions for use, improved identification of patient risk categories and more guidelines-based prescribing intentions for high risk but not low risk patients. The effectiveness of linking the intervention to clinical practice more closely to address implementation barriers will be evaluated in future research.
\end{abstract}

Keywords: Cardiovascular disease, Primary care, Risk communication, Risk assessment, Behaviour change, Evidence-based medicine, Shared decision making, Decision aids, Audit and feedback

\section{Background}

\section{CVD prevention guidelines}

Cardiovascular disease prevention guidelines around the world recommend assessing the absolute risk of a heart attack or stroke in the next $5-10$ years. This is intended to guide the use of blood pressure and cholesterol-lowering medication for those at "high risk" [1,2], based on the most predictive risk factors [3]. Reviews show the absolute risk approach can improve clinical management of CVD risk, patients' risk perception and patients' preventive intentions, compared to treating hypertension and hyperlipidaemia as separate risk factors $[4,5]$. Treatment based on high absolute risk may prevent over-treatment of low-risk patients with an isolated risk factor and under-treatment of highrisk patients with multiple elevated risk factors [6].

\section{The evidence-practice gap}

Despite available guidelines, absolute risk is often not assessed. When it is assessed, it is not necessarily used to guide management decisions [7-10]. A survey of 2000 clinicians across North/South America and Europe found less than half use absolute risk scores regularly. Those who did not use absolute risk were less likely to identify the need for lipid-lowering medication in a hypothetical patient scenario [7]. The consequences are significant. In Australia, 75\% of high-risk patients are not receiving recommended medication to prevent death and disability from CVD, and 25\% of low risk patients are taking medication they are unlikely to benefit from [11]. This evidence-practice gap is estimated to cost the national health system AU\$5.4 billion [12]. Interventions to improve the use of absolute risk assessment in Australia have included pre-consultation risk assessment and integrating risk calculators with medical software [13-15], but these interventions had limited impact on prescribing and have not been translated into clinical practice nationally.

\section{Behavioural barriers}

The Healthy Heart Study aimed to identify and understand behavioural barriers to CVD prevention guidelines in Australia through research with 400 GPs and 600 patients/consumers in 2011-2018 (see Table 1). This project identified barriers not addressed in previous trials, including psychological capability (lack of knowledge about how risk factors relate to medication and lifestyle guidelines, and difficulty understanding/explaining absolute CVD risk); physical opportunity (lack of access to updated evidence and risk communication tools that match Australian guidelines); and reflective motivation (concerns about how to apply guidelines to challenging patient scenarios) [16, 17]. Two strategies have strong evidence to address these issues: audit and feedback can improve knowledge and motivation; and patient decision aids improve risk perception and communication [25, 26]. Audit and feedback programs on this topic were already available to GPs, involving audit of 10 patients with feedback comparing performance to guidelines and peers. There were no available tools to assist GPs with communicating Australian absolute risk guidelines to patients. Systematic reviews of existing online CVD risk communication tools (73 risk calculators and 25 decision aids) found none that met Australian guidelines, used best practice risk communication formats, followed international patient decision aid standards for presenting all management options in a balanced way or met the needs of people with lower health literacy [23, 24]. 
Table 1 Healthy Heart Study findings

\begin{tabular}{|c|c|c|}
\hline & Study description & Implications \\
\hline 1 & GP interviews about CVD risk assessment and management $[16,17]$ & $\begin{array}{l}\text { GPs use a range of CVD risk assessment strategies, and } \\
\text { identified capability (knowledge, communication) opportunity } \\
\text { (access, time) and motivation (habit, concerns about applicability } \\
\text { of guidelines to certain patients) as key barriers to absolute } \\
\text { risk assessment }\end{array}$ \\
\hline 2 & Patient interviews about CVD risk assessment and management [18] & $\begin{array}{l}\text { Patient and GP decision making about CVD risk management } \\
\text { is influenced by perceived risk and attitudes rather than } \\
\text { calculated absolute risk of a CVD event }\end{array}$ \\
\hline 3 & $\begin{array}{l}\text { GP experiment to explore relative influence of absolute risk } \\
\text { vs blood pressure/cholesterol on prescribing [19] }\end{array}$ & $\begin{array}{l}\text { Providing an absolute CVD risk assessment is not sufficient } \\
\text { to overcome GPs' tendency to prescribe medication based } \\
\text { on blood pressure/cholesterol alone }\end{array}$ \\
\hline 4 & Patient "think aloud" study using heart age calculators [20] & $\begin{array}{l}\text { Heart age calculators prompted emotional reactions and } \\
\text { consideration of lifestyle changes, but unexpected 'older' } \\
\text { heart age results were not believable }\end{array}$ \\
\hline 5 & Patient experiment testing heart age versus 5-year absolute CVD risk [21] & $\begin{array}{l}\text { Heart age is easier to recall but also inflates risk perception } \\
\text { and is less credible than 5-year absolute CVD risk, with no } \\
\text { advantage for lifestyle change intentions }\end{array}$ \\
\hline 6 & Patient "think aloud" study using absolute risk calculators [22] & $\begin{array}{l}\text { Absolute CVD risk is more meaningful when provided alongside } \\
\text { a verbal description of the risk category and graphical displays } \\
\text { of intervention effects for both lifestyle and medication }\end{array}$ \\
\hline 7 & Systematic review of existing CVD risk calculators [23] & $\begin{array}{l}\text { There were } 73 \text { CVD risk calculators available online, but none } \\
\text { matched Australian guidelines and they were not suitable for } \\
\text { people with lower health literacy }\end{array}$ \\
\hline 8 & Systematic review of CVD decision aids [24] & $\begin{array}{l}\text { There were } 25 \text { CVD decision aids available online, but none } \\
\text { matched Australian guidelines, few presented both lifestyle } \\
\text { and medication options } \\
\text { in a balanced way, and they were not suitable } \\
\text { for people with lower health literacy }\end{array}$ \\
\hline
\end{tabular}

\section{Aim}

This study aimed to develop, pilot and evaluate the feasibility of a new online platform for the Australian CVD prevention guidelines that links existing strategies (risk calculator, audit and feedback) with a new patient decision aid, in order to (1) help GPs identify guidelinebased recommendations for medication and lifestyle change and (2) communicate this to patients. This paper outlines the results of a theory-based intervention development process, qualitative piloting and quantitative feasibility research for the new combined risk calculator/ decision aid component that was not previously available to Australian GPs.

\section{Methods}

The methods involved 5 different stages:

1. Intervention development based on Behaviour Change Wheel process

2. Co-design of content with GPs

3. GP conference feedback on prototype website

4. GP and patient interview feedback on functional website

5. Feasibility study with GPs using final website over 1 month
Ethical approval was obtained via the University of Sydney and Royal Prince Alfred Hospital Human Research Ethics Committees.

\section{Setting}

The project was conducted in Australia in 2017-2018, based on national CVD prevention guidelines released in 2009 (assessment) and 2012 (management) [1, 27]. The guidelines target General Practitioners (GPs) who can be accessed free of charge under the Medicare system. They are based on the 5-year Framingham model of absolute CVD risk, with different recommendations for:

- Low risk (<10\%): no medication with lifestyle change (smoking, diet, exercise) as needed;

- Moderate risk (10-15\%): lifestyle change initially, unless extra risk factors are present or lifestyle change is ineffective (in which case medication should be considered); and

- High risk (>15\%): both blood pressure/cholesterol lowering medication and lifestyle change.

\section{Stage 1: Intervention development based on the Behaviour Change Wheel process}

The first stage for this paper was to clearly articulate the problem and solutions in behavioural terms, to 
address the issues identified in the Healthy Heart Study. We used the Behaviour Change Wheel (BCW) framework because it synthesises multiple health behaviour theories and models to guide the development of rigorous interventions [28]. According to this framework, behaviour can be attributed to three determinants of behaviour: opportunity (physical and social environment), capability (physical and psychological ability) and motivation (automatic and reflective mechanisms). The framework outlines a process to identify the most important behavioural barriers, the best target population for behaviour change, evidence-based behaviour change techniques and the most feasible delivery mode.

\section{Stage 2: Co-design of content with GPs}

The website content was co-developed with GPs via the 'Ask Share Know: Rapid Evidence for General Practice Decisions: (ASK-GP) Centre of Research Excellence Clinical Laboratory.' This includes a 'knowledge broker' service that provides evidence-based resources for GPs to discuss at small group meetings, which were audio-recorded to supplement field notes ( $\mathrm{CB}$ and MF). Two GP groups were included as they were running discussions at the time of the study. Qualitative data were obtained via field notes to document any suggested changes or problems identified by users as part of the co-design process, with audio recordings used to clarify field notes if needed. A summary of each group discussion was written, and this document was scanned to identify changes to be made for the next website version. No formal qualitative analyses were conducted.

\section{Stage 3: GP conference feedback on prototype website}

The website prototype was piloted at an Australian national conference for General Practitioners in 2017 (GP17) via a presentation and question/answer session (CB) and a tablet placed in an exhibition room stall (CB). Conference data included notes from verbal discussion with stall visitors and a brief written feedback form from attendees with open responses and an overall acceptability rating out of 10 .

\section{Stage 4: GP and patient interview feedback on functional website}

After the GP17 conference, the functional website was developed iteratively based on semi-structured think aloud' user interviews [29] to improve acceptability. A more detailed Framework Analysis had been conducted in 1 GP interview study and 2 patient think aloud studies prior to this stage (see Table 1), so thematic analysis for this stage was limited to notes taken during the interviews ( $\mathrm{CB}$ and $\mathrm{MF}$ ) and from audio recordings, to identify areas to improve. Interviews were conducted at the University of Sydney, via Skype or at the participants' residence/workplace, and were audio-recorded to supplement field notes on intervention features to improve. This involved a concurrent and retrospective verbal protocol where users were asked to think aloud as they used the website, followed by prompting for feedback by the interviewer $(\mathrm{CB})[20]$.

\section{Stage 5: Feasibility study with GPs using final website over 1 month}

A feasibility study to assess acceptability (intended use after initial viewing), demand (actual use after 1 month) and potential efficacy (improved knowledge of recommended interventions for each risk category as per guidelines) [30] was conducted for the final website. A pre-post design was used to maximise feedback from $\sim 100$ end users within the project budget, with oversampling at baseline $(n=123)$ to achieve adequate numbers at follow-up $(n=98)$. GPs were recruited anonymously via an independent recruitment company, which could not provide identifying information about GPs; therefore, it is unknown whether (if any) overlap occurred with the GPs participating in the qualitative stages. The 10-min baseline survey is provided in Additional file 2 and included use of guidelines and absolute CVD risk calculators; self-efficacy for assessing and communicating absolute CVD risk [31]; testing one of 9 hypothetical patients (3 each from low, moderate and high risk categories as per Australian guidelines) with the website to explore whether recommendations matched risk category guidelines for challenging cases [16, 17]; intended use of website features over the next month; open feedback; and demographics. The 4-min followup survey was sent in 3 batches 1 month after completion of the baseline survey to standardise the follow-up period (range 4-6 weeks). It repeated the same questions without the hypothetical patient testing or demographics, with self-reported website usage assessed for the previous month. GPs participated anonymously via a specialist recruitment company and received $\$ 40$ along with access to a login and pre-filled form to apply for continuing professional development points if they chose to complete the self-directed audit and feedback component of the website. Descriptive analyses and confidence interval calculations were conducted using Microsoft Excel, and inferential analyses were conducted using SPSS v25. Chi-squared tests and paired $t$ tests were used to compare categorical data and continuous data, respectively, between baseline and follow-up. Only the final sample of 98 was used in the analysis. 


\section{Results}

\section{Stage 1: Intervention development based on Behaviour} Change Wheel process

Completing the Behaviour Change Wheel process (summarised in Table 2) identified the need to develop a new tool for GPs to use with their patients in consultations, with the following key features (see Figs. 1, 2 and 3 for screenshots of main features, and Additional files 1 and 2 for TIDIER checklist and more detailed intervention content):

1. Interactive CVD risk calculator that combines CVD risk assessment and management algorithms to help GPs identify risk category guidelines [1, 27], based on best practice risk communication principles and patient perceptions of existing CVD risk calculators [20, 22, 32];

2. Personalised patient decision aid that shows the effect of different medication (blood pressure, cholesterol, aspirin), lifestyle (smoking, diet, exercise) and supplement (antioxidants, omega-3, multivitamins) interventions on individual CVD risk to help GPs discuss the benefits and harms of different options [26], based on updated evidence reviews and International Patient Decision Aid Standards to support shared decision making [33]; and

3. Self-directed audit \& feedback including cases that GPs find challenging for CVD risk assessment and communication [16, 17], and comparison of management to guidelines [27], using evidencebased behaviour change techniques [34], based on existing audit and feedback tools familiar to GPs (involving audit of 10 patients with feedback comparing performance to guidelines and peers).

In terms of the BCW framework [28], the intervention targets GPs during consultations and uses education, training and persuasion functions to address psychological capability (decision aid to improve knowledge of applicable guidelines and communication skills; supported by audit and feedback), physical opportunity (by providing the first CVD prevention decision aid based on Australian guidelines and updated evidence) and reflective motivation (by addressing GP concerns through case studies that show how absolute risk can be assessed and communicated; linked to decision aid and part of audit and feedback). It uses multiple behaviour change techniques (information about health consequences, feedback on behaviour, instruction on how to perform a behaviour, action planning, social comparison) delivered via the policy category of guidelines, using an online format for wide accessibility and flexible/sustainable implementation, see Table 2.

\section{Stage 2-4: Qualitative piloting of content, prototype website and functional website}

Table 3 shows how iterative user feedback led to changes to the website over stages $2-4$.

\section{Stage 2: Co-design of content with GPs}

The website content and format was discussed with two practices involved in the ASK-GP CRE ( $n=18$ GPs), including feedback on examples of evidence summaries, decision aids and CVD risk calculators. Changes were made to the evidence summaries to incorporate more practical issues such as cost and inconvenience to patients. GPs asked about complementary and alternative medicine options (fish oil, antioxidants and multivitamins), which were subsequently included in the risk calculator/decision aid even though they had no effect on CVD outcomes, as the GPs felt it would be helpful to show this to patients in order to direct them to more effective options.

\section{Stage 3: GP conference feedback on prototype website} The prototype website was demonstrated at the national GP17 conference in October 2017 via a 30-min

Table 2 Summary of conclusions from the Behaviour Change Wheel framework process

\begin{tabular}{|c|c|c|c|c|}
\hline $\begin{array}{l}\text { Intervention } \\
\text { functions }\end{array}$ & $\begin{array}{l}\text { Behavioural components } \\
\text { served by intervention functions }\end{array}$ & $\begin{array}{l}\text { Behaviour change } \\
\text { techniques (BCTs) to } \\
\text { deliver intervention } \\
\text { functions }\end{array}$ & $\begin{array}{l}\text { Policy categories } \\
\text { through which } \\
\text { BCTs can be } \\
\text { delivered }\end{array}$ & Intervention strategy \\
\hline $\begin{array}{l}\text { - Education } \\
\text { - Training } \\
\text { - Persuasion }\end{array}$ & $\begin{array}{l}\text { - Psychological capability } \\
\text { (understanding role of risk factors, risk } \\
\text { communication) [16, 17] } \\
\text { - Physical opportunity (access to } \\
\text { updated evidence on risk/benefit in } \\
\text { line with Australian guidelines) [16, } 23, \\
24] \\
\text { - Reflective motivation (attitude towards } \\
\text { using guidelines for perceived low/ } \\
\text { high risk cases) [16] }\end{array}$ & $\begin{array}{l}\text { - Information about } \\
\text { health consequences } \\
\text { - Feedback on behaviour } \\
\text { - Instruction on how to } \\
\text { perform a behaviour } \\
\text { - Action planning } \\
\text { - Social comparison }\end{array}$ & - Guidelines & $\begin{array}{l}\text { Online version of guidelines to enable } \\
\text { national access, linked to: } \\
\text { - 5-year risk calculator that integrates } \\
\text { assessment and management guidelines } \\
\text { including clear role of risk factors } \\
\text { - Updated evidence on benefits and harms } \\
\text { for medication + lifestyle options } \\
\text { - Decision aid for patients to improve } \\
\text { communication } \\
\text { - Hypothetical patient cases with feedback } \\
\text { as part of audit and feedback training } \\
\text { exercise [based on existing resources] }\end{array}$ \\
\hline
\end{tabular}


Risk of heart attack/stroke in the next 5 years

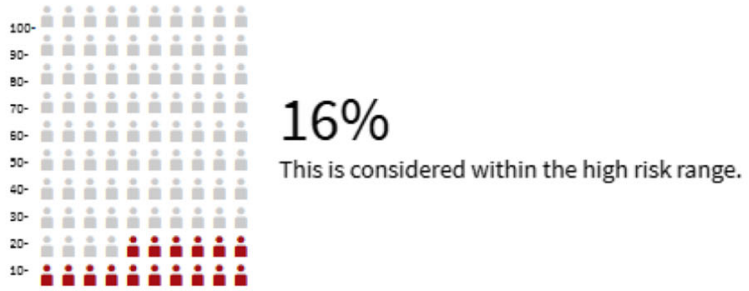

Your current risk of having a heart attack or stroke in the next 5 years is $16 \%$, which is considered high. Imagine 100 people like you sitting in a cinema. 16 of those people will have a heart attack or stroke in the next 5 years if they don't take action.

\section{Intervention options}

Lifestyle
Stop smoking
Mediterranean Diet
Increase physical
activity

\section{Intervention} benefits

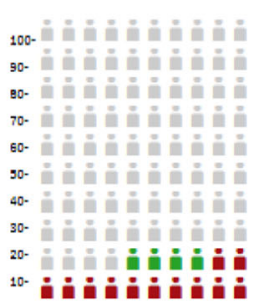

Other

$\begin{gathered}\text { Blood pressure } \\ \text { medication }\end{gathered}$
Cholesterol
medication
Aspirin

Fish Oil (Omega-3) Supplements

\section{Antioxidant} supplements

Multivitamins

If you take a cholesterol lowering medication you could gradually reduce your absolute risk from $16 \%$ to $12 \%$. Your new risk is considered medium

- Cost: Recurring cost for daily pill.

- Side effects: 28 in 1000 people may develop diabetes when on a statin compared to 24 in 1000 on a placebo pill

Print selected intervention option

5 year CVD risk management guidelines

$\begin{array}{ccc}\text { Risk: High } & \text { Lifestyle: } & \text { Medication: } \\ >15 \% & \text { Stop Smoking, Improve diet, } & \text { Cholesterol } \\ & \text { Physical Activity } & \text { Medication, Blood } \\ & & \text { Pressure Medication }\end{array}$

Print decision aid

Reset

Recalculate

Fig. 1 Patient risk calculator and decision aid 


\section{Audit \& Feedback}

\section{Instructions $>$ Clinical resources $>$ Initial data $>$ Initial Summary \\ $\checkmark$ Summary table $\checkmark$ send data $\checkmark$ Give feedback}

\section{Summary Table}

The table below summarises your management of the 10 selected patients compared to the guidelines, and the average for other GPs completing this exercise. Reflect on whether you are happy with current management or not, and select items for your action plan if appropriate.

\begin{tabular}{|c|c|c|c|c|c|c|}
\hline $\begin{array}{l}\text { Clinical } \\
\text { Indicator }\end{array}$ & $\begin{array}{c}\text { Your } \\
\text { Performance }\end{array}$ & $\begin{array}{c}\text { Average GP } \\
\text { performance }\end{array}$ & $\begin{array}{l}\text { Review } \\
\text { patients }\end{array}$ & $\begin{array}{l}\text { Reasons for current } \\
\text { management }\end{array}$ & $\begin{array}{c}\text { Change } \\
\text { management }\end{array}$ & Management Plan \\
\hline $\begin{array}{l}\text { CVD Risk } \\
\text { Assessment } \\
\text { Conducted }\end{array}$ & $\begin{array}{l}60 \% \\
6 / 10\end{array}$ & $80 \%$ & $\begin{array}{l}\text { Jack Doe } \\
\text { Jean Doe } \\
\text { Jake Smith } \\
\text { Janet Smith }\end{array}$ & $\begin{array}{l}\text { Need to do } \\
\text { Other health priorities } \\
\text { Known to be low risk } \\
\text { Need to do }\end{array}$ & $\begin{array}{l}\otimes \\
0 \\
\square \\
\forall\end{array}$ & $\begin{array}{l}\text { Link to Management Plan } \\
\text { Link to Management Plan } \\
\text { Link to Management Plan } \\
\text { Link to Management Plan }\end{array}$ \\
\hline $\begin{array}{l}\text { CVD Risk } \\
\text { discussed with } \\
\text { patient }\end{array}$ & $\begin{array}{l}40 \% \\
4 / 10\end{array}$ & $73 \%$ & $\begin{array}{l}\frac{\text { Jess Smith }}{\text { Jack Doe }} \\
\text { Jean Doe } \\
\text { Jake Smith } \\
\frac{\text { Janet Smith }}{\text { Jay Doe }}\end{array}$ & $\begin{array}{l}\text { Need to do } \\
\text { Need to do } \\
\text { Other health priorities } \\
\text { Known to be low risk } \\
\text { Need to do } \\
\text { Cardiologist already did this }\end{array}$ & $\begin{array}{l}\square \\
\square \\
\square \\
\square \\
\square \\
0\end{array}$ & $\begin{array}{l}\text { Link to Management Plan } \\
\text { Link to Management Plan } \\
\text { Link to Management Plan } \\
\text { Link to Management Plan } \\
\text { Link to Management Plan } \\
\text { Link to Management Plan }\end{array}$ \\
\hline $\begin{array}{c}\text { Lifestyle } \\
\text { management } \\
\text { options discussed } \\
\text { with patient }\end{array}$ & $\begin{array}{l}50 \% \\
5 / 10\end{array}$ & $73 \%$ & $\begin{array}{l}\text { Jeff Smith } \\
\text { Jess Smith } \\
\text { Jack Doe } \\
\text { Jake Smith } \\
\text { Janet Smith }\end{array}$ & $\begin{array}{l}\text { Need to do } \\
\text { Need to do } \\
\text { Need to do } \\
\text { Known to be low risk } \\
\text { Need to do }\end{array}$ & $\begin{array}{l}\mathbb{8} \\
\square \\
\square \\
\square \\
\square\end{array}$ & $\begin{array}{l}\text { Link to Management Plan } \\
\text { Link to Management Plan } \\
\text { Link to Management Plan } \\
\text { Link to Management Plan } \\
\text { Link to Management Plan }\end{array}$ \\
\hline $\begin{array}{l}\text { Medication to } \\
\text { prevent CVD } \\
\text { discussed with } \\
\text { patient }\end{array}$ & $\begin{array}{c}43 \% \\
3 / 7\end{array}$ & $1 \%$ & $\begin{array}{l}\text { Jane Doe } \\
\text { Jeff Smith } \\
\text { Jess Smith } \\
\text { Janet Smith }\end{array}$ & $\begin{array}{l}\text { Cardiologist already discussed } \\
\text { Need to do } \\
\text { Against medication } \\
\text { Need to do }\end{array}$ & $\begin{array}{l}\square \\
\square \\
\square \\
\square\end{array}$ & $\begin{array}{l}\text { Link to Management Plan } \\
\text { Link to Management Plan } \\
\text { Link to Management Plan } \\
\text { Link to Management Plan }\end{array}$ \\
\hline $\begin{array}{l}\text { On both blood } \\
\text { pressure and } \\
\text { cholesterol } \\
\text { medication }\end{array}$ & $\begin{array}{c}33 \% \\
1 / 3\end{array}$ & $1 \%$ & $\begin{array}{l}\text { Jon Doe } \\
\text { Jane Doe }\end{array}$ & $\begin{array}{l}\text { Already on statins, consider bp med } \\
\text { Cardiologist already discussed }\end{array}$ & $\stackrel{\otimes}{\square}$ & $\begin{array}{l}\text { Link to Management Plan } \\
\text { Link to Management Plan }\end{array}$ \\
\hline
\end{tabular}

Save Table Responses

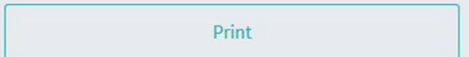

\section{Next steps}

You can anonymously submit your data for feedback from another GP. You will receive access to another summary to give feedback on.

Alternatively you can skip this step, and we will alert you in 6 month's time when you can return to review your data.

Anonymously submit data for feedback from another GP

Complete task and wait for 6 month review

How you compare

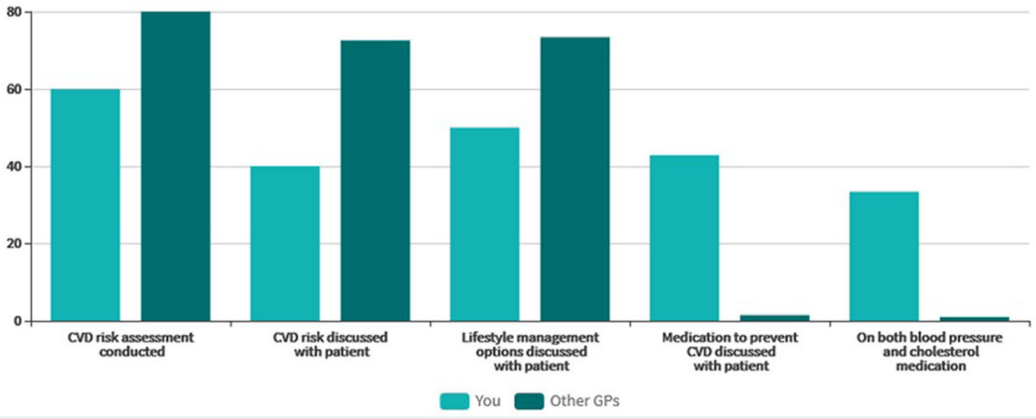

Fig. 2 GP audit and feedback exercise 


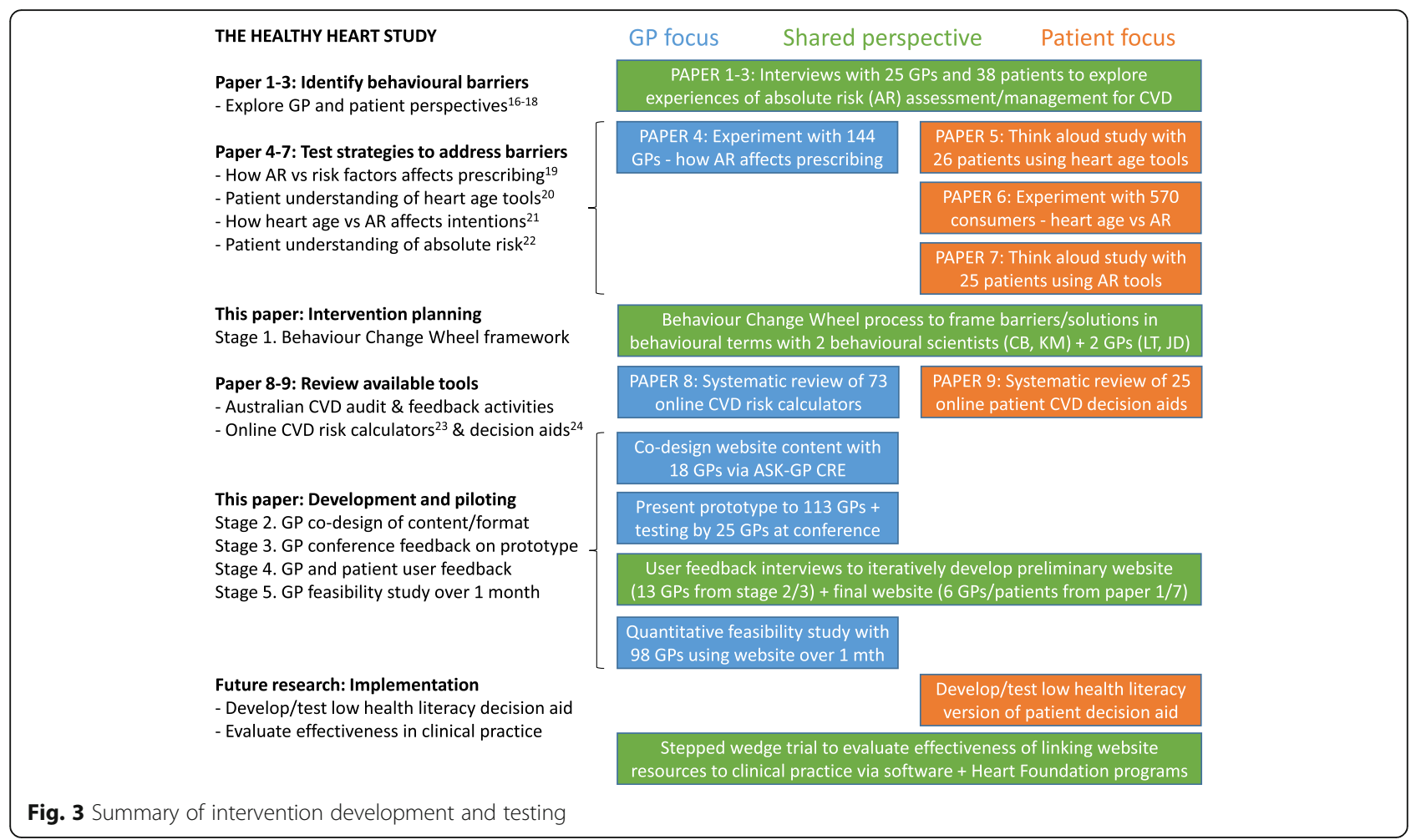

presentation with a question/answer session (attended by $n=113$ delegates) and a conference stall where 25 GPs tested the prototype website on a tablet, of which 16 completed a written feedback form. Verbal and written feedback was positive, with an average 8.4/10 overall acceptability rating and comments such as: "So user friendly, takes relevant clinical data into account, very comprehensive recommendations which are patient as well as doctor friendly".

\section{Stage 4: GP and patient interview feedback on functional website}

In-depth user feedback was obtained from 7 GPs via ASK-GP CRE groups and interested GP17 conference attendees, using semi-structured "think aloud" interviews while using the preliminary website. Suggestions include risk factor and intervention wording changes, automatic calculation of risky drinking and body mass index, and changes to the visual presentation of the risk result to enable black and white printing. These changes were incorporated into the website before further testing with 3 new GPs and 9 patients. Another round of changes was made for the final website halfway through this testing, including a two-page summary of a single intervention as well as the full decision aid. No major content issues were identified in final website testing, but there were some suggestions for implementation to improve accessibility: linking the risk calculator to GP practice software, involving practice nurses and creating a patient/ consumer version of the website that is easier to understand without GP consultation. These issues could not be addressed within the project budget for intervention development. The final website is available at www. auscvdrisk.com.au.

\section{Stage 5: Feasibility study with GPs using final website over 1 month}

Tables 4 and 5 provide an overview of the sample and descriptive capability results before and after using the risk calculator/decision aid component of the website.

\section{Sample description}

The participant characteristics are summarised in Table 4. At baseline, almost all (95\%, $n=93)$ reported using absolute CVD risk calculators, most commonly risk calculators within practice software (Best Practice 35\%, $n=34$; Medical Director 21\%, $n=21$ ) and the National Vascular Disease Prevention Alliance website (www.cvdcheck.org.au; 32\%, $n=31$ ). A lower proportion $(72 \%, n=71)$ of GPs had seen the national CVD prevention guidelines.

\section{Potential efficacy (guideline-based recommendation for risk category)}

At baseline, using the new decision aid at www.auscvdrisk. com.au with a self-selected hypothetical patient significantly increased identification of the correct risk category for low risk cases by $16 \%$ ( $95 \%$ CI 0 to $32 \%$ ), moderate risk 
Table 3 Website development based on iterative user feedback

\begin{tabular}{|c|c|c|}
\hline Development stage & Example user feedback & Major changes made \\
\hline $\begin{array}{l}\text { Stage 1: Intervention } \\
\text { development based on } \\
\text { Behaviour Change Wheel process }\end{array}$ & $\begin{array}{l}\text { Healthy Heart Study GP interview: 'The calculator of } \\
\text { course doesn't include certain factors... if someone does } \\
\text { do a lot of exercise I would...think their risk is probably } \\
\text { lower.' [16] } \\
\text { Healthy Heart Study patient interview: 'The visual } \\
\text { presentation of the result... because it's a picture instead } \\
\text { of numeric, I think I'll take more interest... when you see } \\
\text { red and green....that seems to have more of a impact } \\
\text { on me, you know... the numbers don't, you know?' [22] }\end{array}$ & $\begin{array}{l}\text { - Develop new risk calculator to more clearly explain } \\
\text { risk factor roles in assessment versus management } \\
\text { guidelines (psychological capability), supported by } \\
\text { links to existing audit and feedback strategies } \\
\text { (reflective motivation) } \\
\text { - Link risk calculator to patient decision aid with colour } \\
\text { coded icon arrays to help GPs explain probability of } \\
\text { CVD event to patients (psychological capability) and } \\
\text { access up-to-date intervention effects on their risk } \\
\text { (physical opportunity) }\end{array}$ \\
\hline
\end{tabular}

Stage 2: Co-design of content with GPs

Stage 3: GP conference feedback on prototype website

Stage 4a: GP and patient interview feedback on functional website

Stage 4b: GP and patient interview feedback on final website at www.auscrdrisk.com. au

Stage 5: Feasibility study with GPs using final website over 1 month
GP focus group: "Is it possible you need to quote something along the lines of 'no evidence regarding dose or exact dose' or something? Cos patients ask you a lot of 'how much should I take?'... It could be good with a bit of extra information and a little bit more about the doses and the side effects and costs and so on"

GP conference feedback: 'Improved diet' is very vague and after all, the benefit is only with the Mediterranean diet and has not been shown with other 'improved diets'.

GP interview: 'So are there explanations... for alcohol, you want to put what moderate means...it's not going to calculate BMI for you?

GP interview: 'It's directed towards the risk factor they've actually identified?... I think this is really good the summary... it's really comprehensive... let's not waste any time talking at length about smoking if you're not even considering it... whereas what about your diet... oh yes I'm keen to know about that'

Patient interview: 'With the button where it says print.. it automatically comes up with the print page ahead of viewing it, so maybe it's better to view it first and have the option to print later so you don't have to print it'

GP interview: The patient would be given an ipad... give it to the nurse or hand it back to reception... doing the AUSDIAB [diabetes risk assessment] at reception was really good...enter it on the patient file... if it was high then I would need know

Patient interview: 'I have to talk to the doctor about the cholesterol lowering medication, and blood pressure and aspirin...I can take this [decision aid] with me next time I go to see her'

GP open response comments reflecting key implementation issues:

If it could be somehow linked to practice software so remember to do it and the values are prefilled that would be ideal.'

'Needs to have some in different languages to show people outcomes for those with poor English understanding.'

'More time to be scheduled to counsel patients on lifestyle modification and CVD risk calculator use.'
- Less statistical information and more practical issues for GP evidence summaries

- Include complementary and alternative medicine options to show lack of effect on CVD outcomes

- Rewording risk factors and interventions to be clearer - Automatic calculation of body mass index and risky drinking

- Changed icon array shades to cater to vision impairments and black/white printing

- Add print button for 2 page summary of single intervention selected by GP

- View decision aid information in separate tab before printing

- Change summary table in full 9 option decision aid to more clearly show effects on risk

- No further changes made to GP website or linked resources

- Implementation suggestions still need to be addressed:

1. Auto-population of risk factors from patients' electronic record:

2. Low health literacy version of decision aid;

3. Pre-consultation access to risk calculator/decision aid

- Feedback generally positive with some contrasting views on format preferences

- Confirmed implementation issues identified in stage 4b:

1. Auto-population of risk factors from patients'

electronic record

2. Low health literacy version of decision aid;

3. Pre-consultation access to risk calculator/decision aid cases by 32\% (95\% CI 6 to 57\%) and high risk cases by $50 \%$ (95\% CI 35 to $65 \%$ ); and increased identification of blood pressure and/or cholesterol medication as a recommendation for high risk (see Fig. 4 and Table 5). From 42 GPs who selected a high-risk case, $57 \%(n=24)$ were likely/very likely to prescribe medication. After using the risk calculator, $86 \%(n=36)$ indicated blood pressure or cholesterol medication were recommended, and $69 \%$
( $n=29)$ indicated both were recommended. From 37 GPs who selected a low-risk case, prescribing was similar before $(19 \%, n=7)$ and after $(22 \%, n=8)$ using the risk calculator.

\section{Acceptability (intended use)}

At baseline, most GPs $(88 \%, n=86)$ intended to use the website (at least 1 feature) over the next month. 
Table 4 Feasibility study participant characteristics

\begin{tabular}{ll}
\hline Characteristics & Final sample $(n=98)$ \\
\hline Age (mean) & 52.6 years (SD 8.57) \\
Experience as GP (mean) & 28.0 years (SD 8.98) \\
Gender & \\
Male & $67(68 \%)$ \\
Female & $30(31 \%)$ \\
Other/prefer not to say & $1(1 \%)$ \\
Australian state/territory & \\
New South Wales & $31(32 \%)$ \\
Victoria & $28(29 \%)$ \\
Queensland & $22(22 \%)$ \\
Western Australia & $4(4 \%)$ \\
Tasmania & $2(2 \%)$ \\
Northern Territory & $1(1 \%)$ \\
Australian Capital Territory & $1(1 \%)$ \\
\hline
\end{tabular}

\section{Demand (actual use over 1 month)}

At 1-month follow-up, most GPs $(73 \%, n=72)$ reported using the website (at least 1 feature) in the last month. This included interactive risk calculator features $(73 \%, n=72)$, printed decision aid features (67\%, $n=66)$ and guideline features (52\%, $n=51)$.

\section{Other outcomes}

At 1-month follow-up, there were no significant pre-post differences in reported use of absolute risk assessments; self-efficacy in conducting an absolute CVD risk assessment; or self-efficacy in explaining absolute CVD risk.

\section{Open feedback}

In open feedback, improvements were suggested by $44 \%$ $(n=43)$ and $40 \%(n=39)$ of GPs at baseline and followup, respectively. Of all suggested improvements at baseline, improving access (e.g. via Practice Software integration) was most common (48\%, $n=21)$ followed by formatting changes $(29 \%, n=13$; e.g. colour and font) and content changes $(23 \%, n=10$; e.g. more instructions, different website design features, additional risk factor/effect estimates beyond the scope of the guidelines). Similarly, of all suggested improvements at follow-up, improving formatting was most common (58\%, $n=23)$ followed by improving access $(40 \%, n=41)$ and content changes $(20 \%, n=8)$.

\section{Discussion}

This paper outlines a rigorous theory-based process to develop an intervention to improve the use of guidelines for CVD prevention in Australia, aiming to address GP barriers. It draws on the large literature supporting the use of audit and feedback to change GP prescribing behaviour and use of guidelines, and patient decision aids to improve doctor-patient communication and understanding of risk $[25,26]$. It also adds to the growing use of the Behaviour Change Wheel framework for developing public health interventions to diagnose and target behavioural barriers to public health [28]. From the Behaviour Change Wheel Framework, the education, training and persuasion functions to address psychological capability, physical opportunity and reflective motivation components collectively increased the capacity for GPs to correctly identify CVD risk categories for several scenarios. Improvement in intentions to prescribe to highrisk patients was also observed, although there was little change to prescribing to low-risk patients. Use over 1 month and intentions for future use were high suggesting acceptability to end users.

However, we know that both evidence-based medicine and shared decision making face many barriers more broadly, including environmental and system level issues [35]. The pilot findings suggest several directions for implementation that have already been trialled in the Australian primary care context, which may be effective if

Table 5 Correct risk category and medication recommendation before and after using the website

\begin{tabular}{|c|c|c|}
\hline Selected case & Before using risk calculator & After using risk calculator \\
\hline \multirow[t]{3}{*}{ Low risk $(n=37)$} & Correct risk category: $70 \%$ & Correct risk category: $87 \%$ \\
\hline & \multirow{2}{*}{$\begin{array}{l}\text { Likely/very likely to prescribe } \\
\text { any meds: } 19 \%\end{array}$} & Blood pressure med recommended: 22\% \\
\hline & & Cholesterol med recommended: 22\% \\
\hline \multirow[t]{3}{*}{ Moderate risk $(n=19)$} & Correct risk category: $58 \%$ & Correct risk category: $90 \%$ \\
\hline & \multirow{2}{*}{$\begin{array}{l}\text { Likely/very likely to prescribe } \\
\text { any meds: } 74 \%\end{array}$} & Blood pressure med recommended: 32\% \\
\hline & & Cholesterol med recommended: 42\% \\
\hline \multirow[t]{3}{*}{ High risk $(n=42)$} & Correct risk category: $26 \%$ & Correct risk category: 76\% \\
\hline & \multirow{2}{*}{$\begin{array}{l}\text { Likely/very likely to prescribe } \\
\text { any meds: } 57 \%\end{array}$} & Blood pressure med recommended: 71\% \\
\hline & & Cholesterol med recommended: 83\% \\
\hline
\end{tabular}

Note: see Additional file 1 for details of the 9 hypothetical patient cases ( 3 per risk category; randomised order in survey and also presented in the audit and feedback section of website; developed from Healthy Heart Study GP interviews that identified situations where absolute risk assessment/communication is most challenging $[16,17])$ 


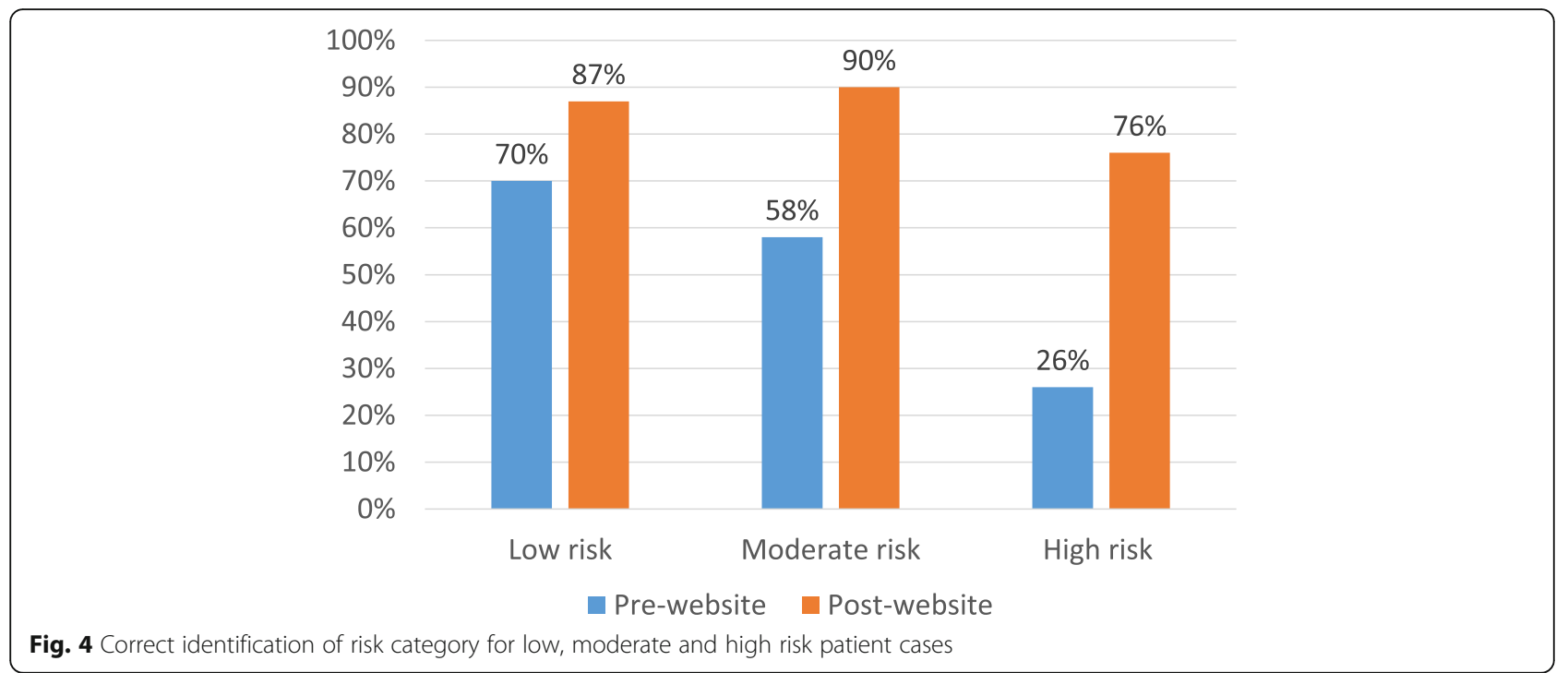

combined with the existing intervention. Specifically, there are three suggestions from GPs and patients in this study that still need to be addressed (see Table 1):

\section{Pre-consultation access to risk calculator/decision} aid: Both GPs and patients suggested that the risk assessment and decision aid could be accessed prior to a consultation before further discussion, ideally with the support of practice nurses and a more consumer-friendly interface. This method has been trialled previously in Australia for CVD risk assessment using a waiting room method [15], but without the additional support of a risk calculator/ decision aid that addressed capability barriers around understanding and communication of risk models. Existing risk calculators did not explain the role of assessment vs management factors, and no decision aids were available that matched 5-year Australian CVD risk guidelines.

2. Auto-population of risk factors from patients' electronic record: This was a suggestion from GPs, who wanted to save time by having the risk assessment linked to patients' recorded risk factors in medical software. This approach has been trialled previously in Australia [13, 14], but access to the risk calculator was restricted to license holders and did not have the additional support of a decision aid to address communication of risk models. Existing tools were inaccessible or did not match Australian guidelines.

3. Low health literacy version of decision aid to meet the needs of people with inadequate skills to access, understand and act on health information. This was suggested by GPs working with diverse communities, who felt the full decision aid with 9 options would be too much information for many of their patients. Low health literacy decision aids have been developed and trialled in Australia using a "universal precautions" approach to health-literate design, but not for CVD prevention [36].

The next stage of the project will use a combination of the above strategies to support the implementation and evaluation of the intervention in clinical practice, as well as aligning with national Heart Foundation programs that aim to improve the use of absolute CVD risk assessment and communication about management options with patients in primary care. The implementation of tools to support shared decision making and health literacy is timely in Australia, with recent policy changes explicitly supporting these two areas [37]. Internationally, there have been calls to use shared decision making in relation to changing CVD prevention guidelines in the UK and US, given lower medication thresholds that may result in many previously 'low risk' patients taking medication for very small benefits in risk reduction [38-40]. Additional strategies may be needed to address the overtreatment of low risk patients, since little change was observed in this study.

\section{Implications for implementation science}

Our results highlight a theoretical issue regarding the difference between implementation (prescribing for high risk) and de-implementation (not prescribing for low risk) [41]. While addressing capability barriers to guidelines appeared to increase intentions for prescribing medication to high-risk patients, there was no improvement in unnecessary prescribing for low risk patients. A recent synthesis of behaviour change theory suggests that behaviour substitution may be needed to address 
the latter situation, but there is little guidance in the literature for how to select such a behaviour at present [41]. More broadly, this project provides a model to other intervention developers for how to apply the theory-based Behaviour Change Wheel framework to identify behavioural barriers to the use of guidelines [28], and co-design an evidence-based intervention with end users to address these barriers. In particular, it illustrates the value of an extensive qualitative evaluation to understand behavioural barriers amongst different targets (GPs and patients) and testing different strategies/formats before trialling an evidence-based intervention, as previous trials in this context had little impact on prescribing and failed to incorporate important knowledge (confusion about the role of different risk factors) and capability (doctor-patient risk communication) issues. The iterative co-design process for website development shows how GP and patient feedback can be incorporated into intervention design, but the timeframe required for this process meant that the qualitative analysis was pragmatic rather than formally thematic. Future intervention designers may benefit from: (1) considering implementation and de-implementation components separately as different behavioural strategies may be needed and (2) long-term planning to allow time for detailed exploration of behavioural barriers initially and more in-depth analysis of purposively sampled user feedback during development.

\section{Strengths and limitations}

This paper highlights the usefulness of mixed qualitative and quantitative methods to understand the context and behavioural barriers to a public health issue, and an iterative user feedback process to develop the intervention. The resulting intervention is evidence-based and acceptable to users in Australia, but needs further testing to evaluate its efficacy and use in clinical practice. The main limitations are (1) the use of pragmatic qualitative analysis methods (i.e. documenting issues in field notes/ summary documents to facilitate quick feedback to website developers rather than formal thematic analysis); (2) the use of a pre-post design to maximise end user feedback, rather than a randomised trial design; and (3) the use of GP self-report rather than GP-patient interactions within a consultation. Future research will focus on addressing these limitations and the implementation suggestions identified in the pilot study.

\section{Conclusions}

Following a theory-based development process and user co-design, the resulting intervention was acceptable to GPs with high intentions for use, improved identification of patient risk categories and some improvement in intended prescribing for high-risk but not low-risk patients. The effectiveness of linking the intervention to clinical practice more closely to address implementation barriers will be evaluated in future research.

\section{Additional files}

Additional file 1: Components of the Australian CVD guidelines intervention. (DOCX $2701 \mathrm{~kb}$ )

Additional file 2: GP survey about cardiovascular disease (CVD) prevention guidelines. (PDF $60 \mathrm{~kb}$ )

\section{Abbreviations}

ASK-GP: Ask, Share, Know, Rapid Evidence Reviews for General Practice Decisions; BCW: Behaviour Change Wheel; CVD: Cardiovascular disease; GP: General Practitioner; UK: United Kingdom; US: United States

\section{Acknowledgements}

We would like to thank the many GPs, patients and consumers who participated in the Healthy Heart Study research that informed the intervention, and the piloting/feasibility studies reported in this paper. We also thank Shannon McKinn for the administrative support for interviews and open response coding; Pinika Patel for collecting the feedback at the GP18 conference stall and organising ASK-GP Centre of Research Excellence GP group discussions; Marguerite Tracy for the advice on RACGP requirements for quality improvement and continuing professional development points; and Aine Heaney for the guidance on audit and feedback structures that are familiar to Australian GPS via NPS MedicineWise clinical e-audits.

\section{Authors' contributions}

CB contributed to the conceptualisation, methodology, design and development of the intervention, data collection, data analysis and interpretation, and the drafting of the manuscript. MF contributed to the development of the intervention, data collection, data analysis, and the revising of the manuscript. KM contributed to methodology, design of the intervention, and the revising of the manuscript. JD contributed to the methodology, design of the intervention, and the revising of the manuscript. LT contributed to the conceptualisation, methodology, design of the intervention, and the revising of the manuscript. All authors read and approved the final manuscript.

\section{Funding}

The study was supported by grants from the National Heart Foundation of Australia (Vanguard Grant 101326), the Royal Australian College of General Practitioners and Therapeutic Guidelines (TGL/RACGP Research Grant

TGL16b), and a National Health and Medical Research Council of Australia Centre of Research Excellence (Ask, Share, Know: Rapid Evidence for General Practice Decisions NHMRC App ID 1106452).

\section{Availability of data and materials}

The datasets used and/or analysed during the current study are available from the corresponding author on reasonable request.

Ethics approval and consent to participate

Ethical approval was obtained via the University of Sydney (for ASK-GP CRE GP group discussions/interviews and GP conference attendee feedback forms/interviews) and Royal Prince Alfred Hospital (for 9 patient interviews and 3 additional GP interviews with no previous exposure to the website via ASK-GP or the conference) Human Research Ethics Committees

\section{Consent for publication}

Not applicable

\section{Competing Interests}

The authors declare they have no competing interests.

\section{Author details}

${ }^{1}$ The University of Sydney, Sydney School of Public Health, ASK-GP Centre of Research Excellence, Rm 128 Edward Ford Building (A27), Sydney, NSW, 
Australia. ${ }^{2}$ Bond University, Faculty of Health Sciences \& Medicine, ASK-GP Centre of Research Excellence, Robina, QLD, Australia.

\section{Received: 18 October 2018 Accepted: 18 July 2019 Published online: 30 August 2019}

\section{References}

1. National Vascular Disease Prevention Alliance. Guidelines for the assessment of absolute cardiovascular disease risk: Approved by the National Health and Medical Research Council; 2009.

2. Joint British Societies Board. Joint British Societies' consensus recommendations for the prevention of cardiovascular disease (JBS3). Heart. 2014;100:1-67.

3. Jackson R, Kerr A, Wells S. Vascular risk calculators essential but flawed clinical tools? Circulation. 2013;127(19):1929-31.

4. Sheridan S, Crespo E. Does the routine use of global coronary heart disease risk scores translate into clinical benefits or harms? A systematic review of the literature. BMC Health Serv Res. 2008;8(1):60

5. Sheridan SL, Viera AJ, Krantz MJ, Ice CL, Steinman LE, Peters KE, Kopin LA, Lungelow D, Research ftCHI, Translation Network Work Group on Global Coronary Heart Disease Risk. The effect of giving global coronary risk information to adults: a systematic review. Arch Intern Med. 2010; 170(3):230-9.

6. Doust J, Sanders S, Shaw J, Glasziou P. Prioritising CVD prevention therapy: absolute risk versus individual risk factors. Aust Fam Phys. 2012;41(10):805-9.

7. Sposito AC, Ramires JAF, Jukema JW, Molina JC, PMd S, Ghadanfar MM, Wilson PWF. Physicians' attitudes and adherence to use of risk scores for primary prevention of cardiovascular disease: cross-sectional survey in three world regions. Curr Med Res Opinion. 2009;25(5):1171-8.

8. Hobbs FDR, Jukema JW, Da Silva PM, McCormack T, Catapano AL. Barriers to cardiovascular disease risk scoring and primary prevention in Europe. QJM. 2010;103(10):727-39.

9. Gupta M, Singh N, Tsigoulis M, Kajil M, Hirjikaka S, Quan A, Teoh H, Verma S Perceptions of canadian primary care physicians towards cardiovascular risk assessment and lipid management. Can J Cardiol. 2012;28(1):14-9.

10. Gupta R, Stocks NP, Broadbent J. Cardiovascular risk assessment in Australian general practice. Aust Fam Phys. 2009;38(5):364-8.

11. Banks E, Crouch SR, Korda RJ, Stavreski B, Page K, Thurber KA, Grenfell R. Absolute risk of cardiovascular disease events, and blood pressure- and lipid-lowering therapy in Australia. Med J Aust. 2016;204:8.

12. Cobiac LJ, Magnus A, Barendregt JJ, Carter R, Vos T. Improving the costeffectiveness of cardiovascular disease prevention in Australia: a modelling study. BMC Public Health. 2012;12:398

13. Peiris D, Usherwood T, Panaretto K, Harris M, Hunt J, Patel B, Zwar N, Redfern J, Macmahon S, Colagiuri S, Hayman N, Patel A. The Treatment of cardiovascular Risk in Primary care using Electronic Decision supOrt (TORPEDO) studyintervention development and protocol for a cluster randomised, controlled trial of an electronic decision support and quality improvement intervention in Australian primary healthcare. BMJ open. 2012;2(6)

14. Peiris D, Usherwood T, Panaretto K, Harris M, Hunt J, Redfern J, Zwar N, Colagiuri S, Hayman N, Lo S, Patel B, Lyford M, MacMahon S, Neal B, Sullivan D, Cass A, Jackson R, Patel A. Effect of a computer-quided, quality improvement program for cardiovascular disease risk management in primary health care the treatment of cardiovascular risk using electronic decision support cluster-randomized trial. Circ Cardiovasc Qual Outcomes. 2015:8(1):87-U142

15. Vagholkar S, Zwar N, Jayasinghe UW, Denney-Wilson E, Patel A, Campbell T, Harris MF. Influence of cardiovascular absolute risk assessment on prescribing of antihypertensive and lipid-lowering medications: A cluster randomized controlled trial. Am Heart J. 2014;167(1):28-35.

16. Bonner $C$, Jansen J, McKinn S, Irwig L, Doust J, Glasziou P, Hayen A, McCaffery K. General Practitioners' use of different cardiovascular risk assessment strategies: A qualitative study. Med J Aust. 2013;199(7):485-9.

17. Bonner C, Jansen J, McKinn S, Irwig L, Doust J, Glasziou P, McCaffery K. Communicating cardiovascular disease risk: an interview study of General Practitioners' use of absolute risk within tailored communication strategies. BMC Fam Pract. 2014;15:106.

18. Bonner C, Jansen J, McKinn S, Irwig L, Doust J, Glasziou P, McCaffery K. How do General Practitioners and patients make decisions about cardiovascular disease risk? Health Psychol. 2015;34(3):253-61.
19. Jansen J, Bonner C, McKinn S, Irwig L, Glasziou P, Doust J, Teixeira-Pinto A Hayen A, Turner R, McCaffery K. General practitioners' use of absolute risk versus individual risk factors in cardiovascular disease prevention: an experimental study. BMJ Open. 2014;4(5):e004812.

20. Bonner C, Jansen J, Newell B, Irwig L, Glasziou P, Doust J, Dhillon H, McCaffery K. I don't believe it, but i'd better do something about it: patient experiences of online heart age risk calculators. J Med Internet Res. 2014; 16(5):118-29.

21. Bonner C, Jansen J, Newell BR, Irwig L, Teixeira-Pinto A, Glasziou P, Doust J, McKinn S, McCaffery K. Is the 'heart age' concept helpful or harmful compared to absolute cardiovascular disease risk? An experimental study. Med Dec Making. 2015.

22. Bonner C, McKinn S, Lau A, Jansen J, Doust J, Trevena L, McCaffery K. Heuristics and biases in cardiovascular disease prevention: how can we improve communication about risk, benefits and harms? Patient Educ Couns. 2018;101(5):843-53.

23. Bonner C, Fajardo MA, Hui S, Stubbs R, Trevena L. Clinical validity, understandability, and actionability of online cardiovascular disease risk calculators: systematic review. J Med Internet Res. 2018;20(2):e29.

24. Bonner C, Patel P, Fajardo MA, Zhuang R, Trevena L. Online decision aids for primary cardiovascular disease prevention: systematic search, evaluation of quality, and suitability for low health literacy patients. BMJ Open. 2019;9(3):e025173.

25. Ivers N, Jamtvedt G, Flottorp S, Young JM, Odgaard-Jensen J, French SD, O'Brien MA, Johansen M, Grimshaw J, Oxman AD. Audit and feedback: effects on professional practice and healthcare outcomes. Cochrane Database of Systematic Reviews. 2012;6:CD000259.

26. Stacey $D$, Légaré $F$, Lewis $K$, Barry MJ, Bennett $C L$, Eden KB, Holmes-Rovner M, Llewellyn-Thomas H, Lyddiatt A, Thomson R, Trevena L. Decision aids for people facing health treatment or screening decisions. Cochrane Database Syst Rev. 2017:4:CD001431

27. National Vascular Disease Prevention Alliance, Guidelines for the management of absolute cardiovascular disease risk. Approved by the National Health and Medical Research Council. 2012

28. Michie S, van Stralen MM, West R. The behaviour change wheel: a new method for characterising and designing behaviour change interventions. Implement Sci. 2011;6:42.

29. Kuusela H, Paul P. A comparison of concurrent and retrospective verbal protocol analysis. Am J Psychol. 2000;113(3):387-404.

30. Bowen DJ, Kreuter M, Spring B, Cofta-Woerpel L, Linnan L, Weiner D, Bakken S, Kaplan CP, Squiers L, Fabrizio C, Fernandez M. How we design feasibility studies. Am J Prev Med. 2009;36(5):452-7.

31. Francis J, Eccles M, Johnston M, Walker A, Grimshaw J, Foy R, Kaner E, Smith $L$, Bonetti D. Constructing questionnaires based on the theory of planned behaviour: a manual for health services researchers; 2004.

32. Trevena $\sqcup$, Zikmund-Fisher BJ, Edwards A, Gaissmaier W, Galesic M, Han PK, King J, Lawson ML, Linder SK, Lipkus I, Ozanne E, Peters E, Timmermans D, Woloshin S. Presenting quantitative information about decision outcomes: a risk communication primer for patient decision aid developers. BMC Med Inform Decis Mak. 2013;13(2):S7.

33. Elwyn G, O'Connor AM, Bennett C, Newcombe RG, Politi M, Durand M-A, Drake E, Joseph-Williams N, Khangura S, Saarimaki A, Sivell S, Stiel M, Bernstein SJ, Col N, Coulter A, Eden K, Härter M, Rovner MH, Moumjid N, Stacey D, Thomson R, Whelan T, van der Weijden T, Edwards A. Assessing the quality of decision support technologies using the International Patient Decision Aid Standards instrument (IPDASi). PLoS One. 2009;4(3):e4705.

34. Michie S, Richardson M, Johnston M, Abraham C, Francis J, Hardeman W, Eccles MP, Cane J, Wood CE. The behavior change technique taxonomy (v1) of 93 hierarchically clustered techniques: building an international consensus for the reporting of behavior change interventions. Ann Behav Med. 2013;46(1):81-95.

35. Scholl I, LaRussa A, Hahlweg P, Kobrin S, Elwyn G. Organizational- and system-level characteristics that influence implementation of shared decision-making and strategies to address them - a scoping review. Implement Sci. 2018;13:40.

36. McCaffery KJ, Holmes-Rovner M, Smith SK, Rovner D, Nutbeam D, Clayman ML, Kelly-Blake K, Wolf MS, Sheridan SL. Addressing health literacy in patient decision aids. BMC Med Inform Decis Mak. 2013;13:S10.

37. Trevena L, Shepherd HL, Bonner C, Jansen J, Cust AE, Leask J, Shadbolt N, Del Mar C, McCaffery K, Hoffmann T. Shared decision making in Australia in 2017. Zeitschrift Fur Evidenz Fortbildung Und Qualitaet Im Gesundheitswesen. 2017;123-124:17-20. 
38. Goldacre B. Statins are a mess: we need better data, and shared decision making. BMJ. 2014;348:93306.

39. Montori VM, Brito JP, Ting HH. Patient-centered and practical application of new high cholesterol guidelines to prevent cardiovascular disease. JAMA. 2014;311(5):465-6.

40. Redberg RF, Katz MH. Statins for primary prevention the debate is intense, but the data are weak. JAMA. 2016;316(19):1979-81.

41. Patey A, Hurt C, Grimshaw J, Francis J. Changing behaviour 'more or less'-do theories of behaviour inform strategies for implementation and deimplementation? A critical interpretive synthesis. Implement Sci. 2018;13:134.

\section{Publisher's Note}

Springer Nature remains neutral with regard to jurisdictional claims in published maps and institutional affiliations.

Ready to submit your research? Choose BMC and benefit from:

- fast, convenient online submission

- thorough peer review by experienced researchers in your field

- rapid publication on acceptance

- support for research data, including large and complex data types

- gold Open Access which fosters wider collaboration and increased citations

- maximum visibility for your research: over $100 \mathrm{M}$ website views per year

At BMC, research is always in progress.

Learn more biomedcentral.com/submissions 